\title{
Type II Myeloblasts Measurement
}

National Cancer Institute

\section{Source}

National Cancer Institute. Type II Myeloblasts Measurement. NCI Thesaurus. Code C92284.

The determination of the amount of type II myeloblasts present in a sample. 